\title{
Viktigheten av studentaktiv og praksisnær læring for utformingen av en matteknolog
}

\author{
Lisbeth Mehli ${ }^{1}$, Anita Nordeng Jakobsen ${ }^{1}$, Rolf Jonas Persson ${ }^{2}$, Ragnhild Lyngved Staberg ${ }^{3}$ \\ ${ }^{1}$ Institutt for bioteknologi og matvitenskap, NTNU - Norges teknisk-naturvitenskapelige universitet \\ ${ }^{2}$ Institutt for fysikk, NTNU - Norges teknisk-naturvitenskapelige universitet \\ ${ }^{3}$ Institutt for loererutdanning, NTNU - Norges teknisk-naturvitenskapelige universitet
}

\begin{abstract}
Bachelorutdanningen i matteknologi ved NTNU utdanner kandidater som kan gå inn i en rekke ulike roller innen matindustri og forvaltning; eksempelvis innen kvalitetsarbeid og analyser, innovasjon og produktutvikling, matproduksjon og forskning. Matteknologen er en allrounder. Som et ledd i å optimalisere studentenes læring og øke gjennomstrømmingen, ønsket vi å finne ut mer om hvilke oppfatninger og forestillinger studentene har om studiet. Hva er viktig i studiet i utformingen av en matteknolog? Hvilke laringsaktiviteter opplevde de som nyttige i forhold til å forstå pensum bedre? Kan læringsaktiviteter med utgangspunkt fra arbeidslivet øke forståelsen av faglige tema? Dette er spørsmål som ble stilt til studenter fra 1., 4. og 6. semester under utdanning og uteksaminerte kandidater fra bachelorutdanningen. Undersøkelsen ble gjennomført med fokusgruppeintervjuer med påfølgende tematisk analyse av data. Studentenes holdninger og forventninger, samt studiets oppbygning, vurderingsmetoder og grad av studentaktiv læring kan påvirke læringsutbyttet i løpet av utdanningen. Ifølge studentenes egne erfaringer er de viktigste elementene i utformingen av en matteknolog innslag av forskjellige relevante og praksisnære studentaktiviteter. Spesielt fremheves den 5 måneders lange praksisperioden i 4. semester innen industri eller forskning som utfordrende og lærerik med tydelig relevans for arbeidslivet. Dette gir studentene et klart innblikk i hvilke jobber eller roller de kan ta etter utdanningen. Arbeid med reelle problemstillinger alene eller i grupper fremheves også som en type praktisk arbeid som studentene erfarer øker læringsutbyttet.
\end{abstract}

\section{INNLEDNING}

Matindustrien er en viktig del av norsk bioøkonomi. Den omsetter for over 340 milliarder kroner årlig og har et stort behov for fremtidig kompetanse i alle ledd (Mat og industri, 2018). En av fem sysselsatte har høyere utdanning og andelen er økende (Mat og industri, 2018). En matindustri i endring krever profesjonsutøvere som har motivasjon, kompetanse, nettverk og tverrfaglig tilnærming. Studentene er fremtidige endringsagenter som må kunne løse komplekse globale utfordringer (Meld. St. 4, 20182019).

Studenters holdninger, oppfatninger og forventninger om framtidig karriere skapes av erfaringer under utdanningen. Bruk av ulike undervisnings- og vurderingsmetoder er viktig, det påvirker studentenes læringsutbytte og dermed studieresultatet (Savelsbergh et al., 2016). Utdanninger, der studenter opplever god kontakt med arbeidslivet gjør at de evner å bruke sin faglige kompetanse i arbeidslivet (Stortingsmelding nr. 16, 2016-2017). Studenter ønsker seg større muligheter for mer praksis, mer oppgaveløsning med bedrift, mer informasjon om sine muligheter $\mathrm{i}$ arbeidsmarkedet og mer arbeidslivsrettet undervisning (Rambøll, 2019). Både faglig kompetanse, generiske ferdigheter som kritisk tenking, sosial kompetanse, selvrefleksjon, samfunns-bevissthet, kommunikasjons- og samarbeidsevner samt bransjeforståelse og evne til å tilegne seg ny kunnskap er viktig for arbeidsgiverne framover (Small et al., 2018; Støren et al., 2019).

Sikring av arbeidslivsrelevans og kalibrering av utdanningen til behovene i samfunnet, har vært viktig i matteknologistudiet (Karlsen et al., 2015; Jakobsen et al., 2020). Studieprogrammet har tett kontakt med arbeidslivet gjennom eksempelvis praksisstudier i utdanningen, utvikling av undervisningsmoduler i samarbeid med industri og offentlig forvaltning (Karlsen et al., 2015; Jakobsen et al., 2020), bruk av ekskursjoner og gjesteforelesere (Karlsen et al. 2015; Jakobsen \& Waldenstrøm 2017), og bruk av 
«studentforskere» i bacheloroppgaver i samarbeid med industri og forskningsinstitutt (Lerfall \& Jakobsen, 2019). Industrielle case brukt som campusundervisning sammen med digitale forelesninger (omvendt klasserom (OK)) oppleves av studentene som relevante for arbeidslivet (Jakobsen et al., 2020). Studentenes egne erfaringer ble trukket inn i diskusjonene i casene og bidro til ytterligere refleksjon og sammenligning av ulike bransjers tilnærming til lignende problemstillinger (Jakobsen et al., 2020). Studenter kan foretrekke forelesninger med lærer fremfor videoforelesninger, men forelesningene kan gjerne inneholde ulike aktiviteter som engasjerer og motiverer, noe som igjen fremmer studentenes holdninger og selvtillit og gir bedre studieresultat sammenlignet med studenter med tradisjonelle forelesninger i utdanningen (Miller et al., 2013; Bishop \& Verleger, 2013).

I denne undersøkelsen er målet å få kunnskap om hva som engasjerer og motiverer ulike studentgrupper i matteknologi til bedre læring og økt læringsutbytte. Undersøkelsen skal bidra til å avdekke endringen i studentenes holdninger til studiet under utdanningen, og hvordan disse endringene påvirker studentenes forståelse og læring av fagstoffet.

\section{Forskningsspørsmål:}

1. Hva er viktig i studiet i utformingen av en matteknolog?

2. Hvilke læringsaktiviteter opplever studentene som viktige for å forstå fagstoffet?

3. Kan læringsaktiviteter med utgangspunkt fra arbeidslivet øke forståelsen av faglige tema?

\section{METODE}

Bachelor i matteknologi ${ }^{1}$ (fra høsten 2021 endres navnet til Matvitenskap, teknologi og bærekraft) er ett treårig bredt studium som kombinerer realfag og teknologi (Fig. 1). Utdanningen har en periode på 5 mnd. med praksis i 4 . semester (Fig. 1).

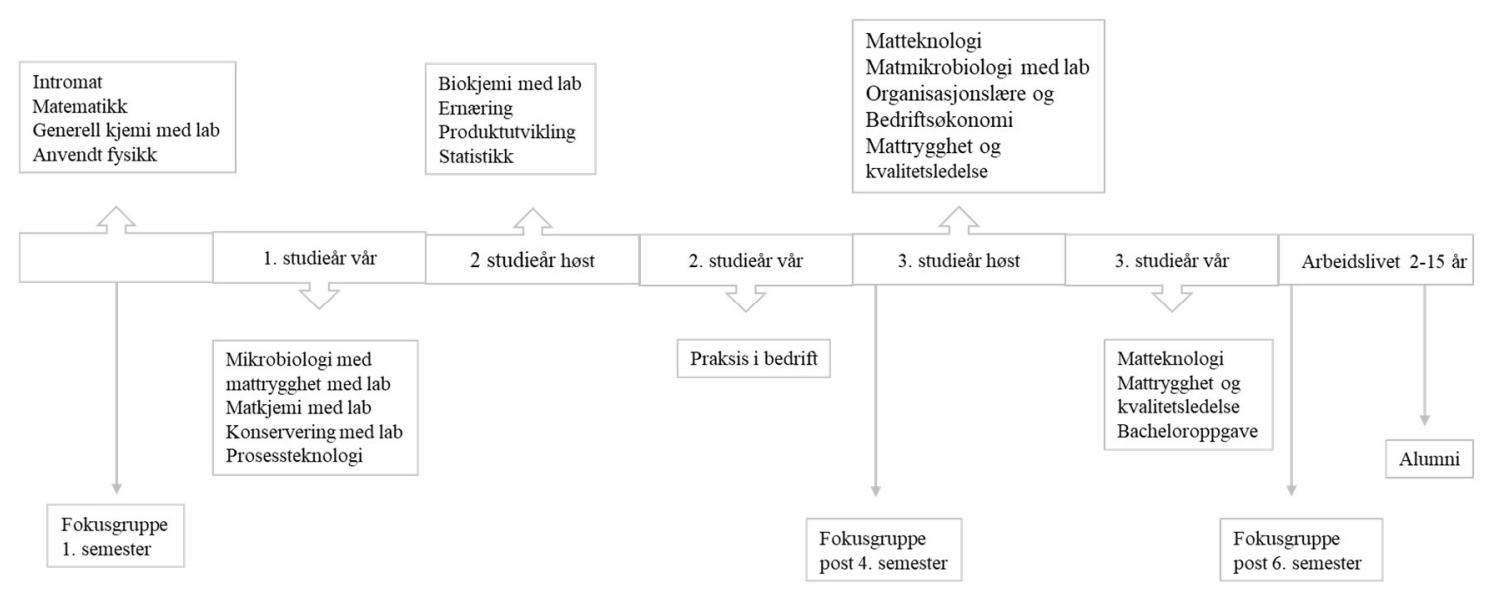

Fig. 1. Oppbygning av bachelorstudiet $i$ matteknologi ved NTNU for studenter tatt opp $i$ 2018. Tidspunkt $i$ utdanningen for studentenes deltagelse i de ulike fokusgrupper er angitt.

Utvalg og datainnsamling. Det ble benyttet kvalitativ metode, i form av fokusgruppeintervjuer (Robson \& McCartan, 2016; Rabiee, 2004). Utvalget bestod av studenter fra tre ulike stadier i utdanningen; 1. semester (4 studenter), etter 4 . semester (12 studenter) og etter 6.semester (5 studenter), samt uteksaminerte kandidater (alumni) med 2-15 års arbeidserfaring (6 kandidater), totalt 27 studenter (Fig.1). Informantene ble selektert på bakgrunn av selvutvelgelse, studentene meldte seg selv til å delta i studien. Studentene ble intervjuet i grupper på 2 - 4 personer. Intervjuet var semistrukturert (Cohen et al., 2018). Studentene ble spurt om hva som betyr mest for utformingen av en matteknolog, hvilke læringsaktiviteter de opplevde som nyttige $\mathrm{i}$ forhold til å forstå pensum bedre, og hvorvidt læringsaktiviteter med utgangspunkt i arbeidslivet kan øke forståelsen av faglige tema.

\footnotetext{
${ }^{1}$ https://www.ntnu.no/studier/mtmat
} 
Dataanalyse. Dataene ble transkribert og analysert ved hjelp av tematisk analyse (Braun \& Clarke, 2006) $\mathrm{i}$ henhold til Castleberry \& Nolen (2018) sine fem trinn. To av forskerne gikk gjennom transkripsjonene hver for seg og kodet dataene uavhengig av hverandre. Det ble benyttet åpen koding og en induktiv tilnærming. Kodene ble sammenlignet og diskutert og lagt inn i NVivo (QSR International Pty Ltd). Overordnede koder eller temaer ble i fellesskap konstruert basert på de første kodene.

\section{RESULTATER OG DISKUSJON}

Denne undersøkelsen viser at en praksisperiode i utdanningen og praksisnære aktiviteter eksempelvis i form av nettverksbygging, er viktig for utformingen av en matteknolog. Studentene trakk fram praksis, nettverk og utdanningen generelt som viktige elementer (Fig. 2). Spesielt studentene etter 4.semester og

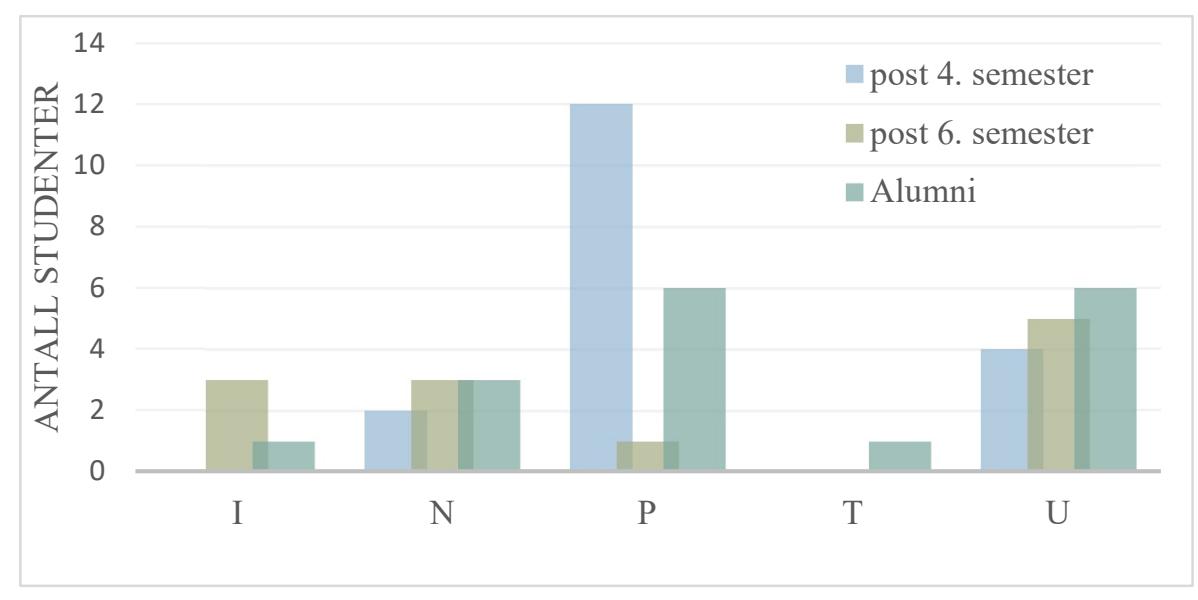

Fig. 2. Antall studenter som nevner at Interesse (I), Nettverk (N), Praksis (P), Tilfeldigheter (T) og Utdanningen generelt $(U)$ er viktig i utformingen av en matteknolog. Antall deltagere fra de ulike studentgruppene er post 4. semester (12), post 6. semester (5), alumni (6). Studentene i 1. studieår ble ikke spurt om hva som er viktig $i$ utformingen av en matteknolog.

alumni pekte på praksisperioden som viktig, informant 2 (0037; alumni): Da tenker jeg de praktiske tilnoermingene som bachelorstudiet har til industriell matteknologi. Vi loerte mye fra en praktisk vinkel og tilbake til praksisperioden hvor vi var ute og virkelig så hvordan ting ble gjort, det tror jeg har mye å si for utformingen. Dette oppleves også av studentene rett etter 4. semester, informant 2 (0024, post 4. semester): A bare se alle de ulike bedriftene folk har voert, så ser man at det er en mulighet for å gå til disse plassene og få en jobb på en måte, det er viktig. Praksisperioden gir studentene et klart innblikk i hvilke jobber eller roller de kan ta etter utdanningen, informant 1 ( 0019 , post 4. semester): Det er selvfølgelig praksis. Hva forelesere sier om hva vi kan forvente i arbeidslivet og hva industrien og arbeidslivet forventer av oss. Det tror jeg nok er med på å forme oss. Viktigheten av en praksisperiode med autentiske erfaringer, interaksjoner med medstudenter og bedrifter i utdanningen fremheves også i andre studier (Trevallion, 2017; Velle et al., 2017).

Det er store individuelle forskjeller i denne undersøkelsen i forhold til hvordan hver enkelt student tenker de lærer best (Fig. 3). Studentene i 1. semester tenker ikke på karriere og arbeidsliv, og trekker derfor ikke fram arbeidslivsaktiviteter i like stor grad som eldre studenter og alumni (Fig. 3). Informant 2 (0036, alumni): Alt som kan laeres med praksis og en øvelse er så mye lettere enn à bare lese. Det å få ta og føle på det. Prøve og feile. Det er viktig. Praktisk øvelse. Bruk av case i undervisningen engasjerer studentene etter 1. semester (Fig. 3). Post 4. semester, informant 1 (0020): Det kan vaere vanskelig å sitte $i$ et klasserom og lese noe, uten at du har noe peiling på hvordan dette brukes $i$ bedriften, så eksempler fra ekte arbeidssituasjoner og slikt hjelper meg veldig å forstå hvordan det faktisk kan brukes på ordentlig. Tidspunkt i utdanningen hadde mye å si for om studentene mente at arbeidslivsrelaterte læringsaktiviteter var nyttige for forståelsen av faglige tema. Desto lengre opp i studiet studentene var, desto mer verdsatte de arbeid med autentiske situasjoner, eller case (Fig. 3). I en rapport fra NOKUT om praksis i fremragende miljøer fremheves autentiske arbeidsformer og realistiske læringssituasjoner som undervisningsformer som gir god læring, økt motivasjon og synliggjør karrieremuligheter tydeligere for studentene (Bråten \& Kantardjiev, 2019). 


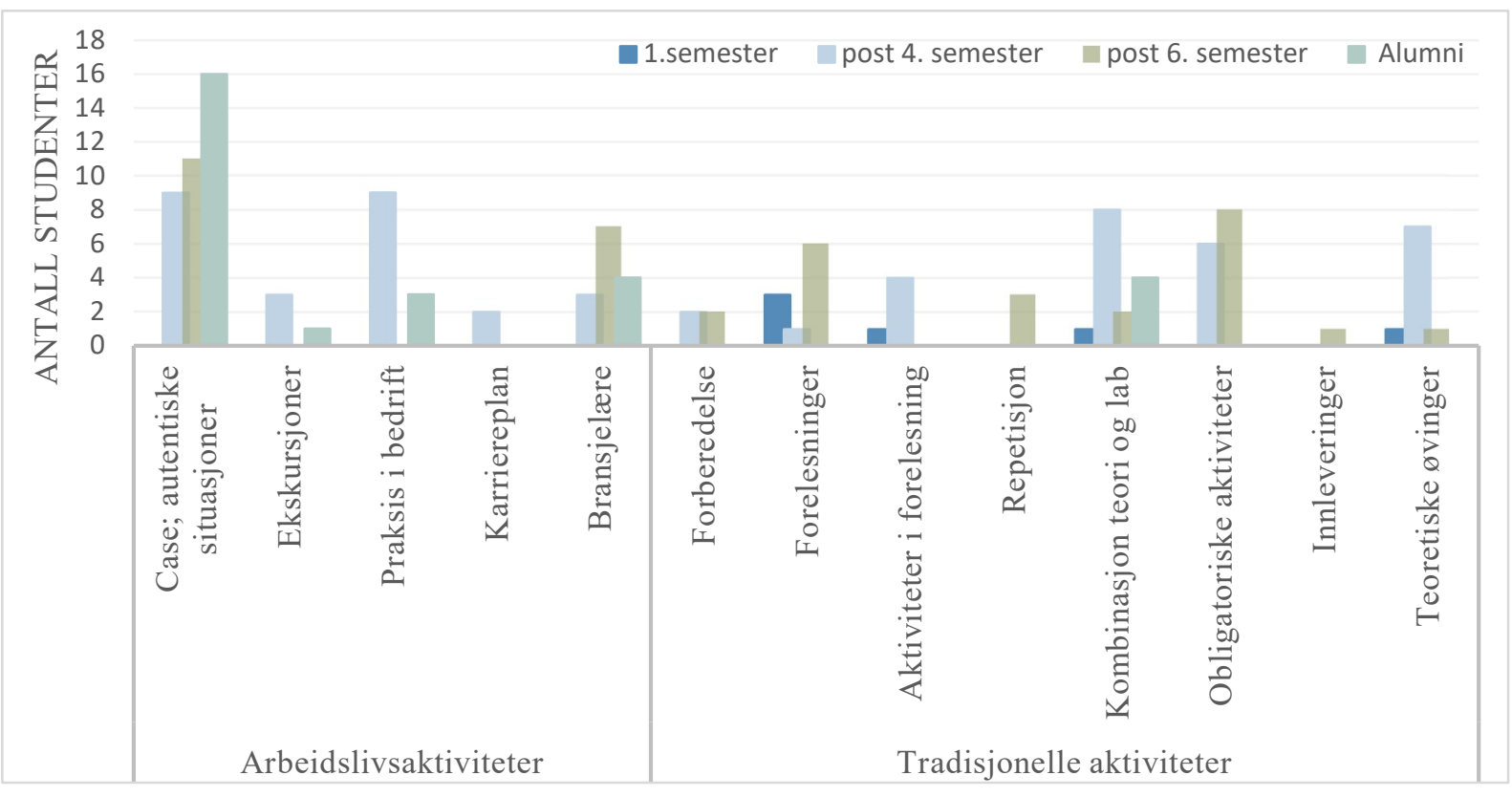

Fig. 3 Antall studenter fra ulike stadier $i$ utdanningen som opplever at ulike laeringsaktiviteter er nyttige med tanke på å forstå pensum bedre og som nevner ulike aktiviteter fra arbeidslivet som kan benyttes for å forstå fagstoffet bedre. Antall deltagere fra de ulike studentgruppene er 1. semester (4), post 4. semester (12), post 6. semester (5), alumni (6).

Studentene i de utvalgte semestrene i denne utdanningen fremhever ulike tradisjonelle aktiviteter i som positive, eks. forelesninger og teoretiske øvinger (Fig. 3). Mange studenter foretrekker forelesninger (lese selv, arbeide alene, delta på forelesninger) (Karlsen et al., 2015) fordi undervisningen oppfattes som eksamensrelevant (Thingnes et al., 2015), men undervisningsmetoden bidrar normalt ikke til utvikling av generiske ferdigheter som er ettertraktet (Virtanen \& Tynjälä 2019). Som et alternativ til tradisjonelle forelesninger er aktive forelesninger prøvd ut med signifikante resultater (Miller et al., 2013). En kombinasjon av teori og laboratoriearbeid fremheves av alle studentgrupper som en arbeidsform som gir økt forståelse av teorien (Fig. 3).

\section{KONKLUSJON OG VIDERE ARBEID}

Praksisperioden og de praksisnære undervisningsmetodene som allerede er i bruk ved bachelorutdanningen i matteknologi er sentrale deler ifølge våre egne studenter og kandidater med arbeidserfaring. Denne undersøkelsen er en del av en større undersøkelse om studentenes holdninger, forventninger og oppfatninger om denne bachelorutdanningen som vil bidra til å tilpasse utdanningen og forberede studentene bedre til fremtidige roller og oppgaver i arbeidslivet.

\section{REFERANSER}

Bishop, J. L., \& Verleger, M. A. (2013). The Flipped Classroom: A Survey of the Research. 120th American Society for Engineering Education Annual Conference and Exposition, 30, 1-18

Braun, V., Clarke, V. (2006). Using thematic analysis in psychology. Qualitative Research in Psychology 3, 77101.

Bråten, H. \& Kantardjiev, K. (2019). Praksis i fremragende miljøer. Innblikk i arbeidet med praksis i tre Sentre for fremragende utdanning. NOKUT. Rapportnummer: 14-2019 ISSN-nr 1892-1604

Castleberry, A. \& Nolen, A. (2018). Thematic Analysis of Qualitative Research Data: Is It as Easy as It Sounds? Currents in Pharmacy Teaching and Learning, 10(6), 807-815.

Cohen, L., Manion, L., Morrison, K. (2018). Research Methods in Education. Eighth Edition. London, New York: Routledge. 
Jakobsen, A. N., Mehli, L., \& Hoel, S. (2020). Arbeidslivets perspektiv inn i klasserommet via filmatiserte case. Uniped, 43(4), 312-330. https://doi.org/10.18261/issn.1893-8981-2020-04-04

Jakobsen, A. N. \& Waldenstrøm, L. (2017). Fra lærerstyrt undervisning til varierte læringsformer. Nordic Journal of STEM Education, 1(1), 319-327. https://doi.org/https://doi.org/10.5324/njsteme.v1i1.2330

Karlsen, H., Mehli, L., Wahl, E., Staberg, R.L. (2015). Teaching outbreak investigations to undergraduate food technologists. British food journal 117: 766-778. https://doi.org/10.1108/BFJ-02-2014-0062

Lerfall, J. og Jakobsen, A. N. (2019). Involvering av bachelor- og masterstudenter i eksternfinansiert sjømatforskning ved NTNU - Case: Prosjektet Innovative teknologiske løsninger for økt holdbarhet i lettprosessert sjømat Norsk Sjømat, 1, 14-16.

Meld. St. 4 2018-2019. Langtidsplan for forskning og høyere utdanning 2019-2028 Regjeringen.no

Meld. St nr. 16 2016-2017. Kultur for kvalitet i høyere utdanning. Regjeringen.no

Miller, C. J., McNear, J., Metz, M. J. (2013) A comparison of traditional and engaging lecture methods in a large, professional-level course Adv Physiol Educ 37: 347-355; doi:10.1152/advan.00050.2013.

Rambøll, (2019) Kandidatundersøkelsen 2018.

Rabiee, F. (2004). Focus-group interview and data analysis. Proceedings of the Nutrition Society, 63, 655660.Small, L., Shacklock, K. \& Marchant, T. (2018). Employability: a contemporary review for higher education stakeholders. Journal of Vocational Education \& Training, 70(1), 148-166. https://doi.org/10.1080/13636820.2017.1394355

Robson, C., McCartan, K. (2016). Real world research. Fourth Edition. West Sussex: John Wiley \& Sons Ltd.

Savelsbergh, E.R., Prins, G.T., Rietbergen, C., Fechner, S., Vaessen, B.E., Draijer, J.M., Bakker, A., Effects of Innovative Science and Mathematics Teaching on Student Attitudes and Achievement: A Meta-Analytic Study, Educational Research Review (2016), doi: 10.1016/ j.edurev.2016.07.003.

Støren, L. A., Reiling, R. B., Skjelbred, S.-E., Ulvestad, M. E., Carlsten, T. C. \& Olsen, D. S. (2019). Utdanning for arbeidslivet: Arbeidsgivers forventninger til og erfaringer med nyutdannede fra universiteter, høgskoler og fagskoler (NIFU-rapport). Hentet fra http://hdl.handle.net/11250/2589732

Thingnes, E. L., Stalsberg, R. og Sitter, B. (2015). Er forelesninga effektiv, interessant og meningsfull? Oppfatninger om og betydningen av forelesninger som undervisningsform. Uniped, 38(4), 390-397.

Trevallion D. (2020) Changing the Professional Identity of Food Technology Teachers in New South Wales, Australia. In: Rutland M., Turner A. (eds) Food Education and Food Technology in School Curricula. Contemporary Issues in Technology Education. Springer, Cham. https://doi.org/10.1007/978-3-03039339-7 11

Velle, G., Hole, T., Førland, O., Simonelli, A., \& Vandvik, V. (2017). Developing work placements in a discipline-oriented education. Nordic Journal of STEM Education 1 (1), 287-306.

Virtanen, A. \& Tynjälä, P. (2019) Factors explaining the learning of generic skills: a study of university students' experiences, Teaching in Higher Education, 24:7, 880-894, DOI: $10.1080 / 13562517.2018 .1515195$ 